\title{
Degradabilidade ruminal e balanço energético em vacas leiteiras a pasto suplementadas com torta de dendê
}

\author{
Ruminal degradability and energy balance in dairy cows on pasture supplemented with palm \\ kernel cake
}
SILVA, Raimundo Luiz Nunes Vaz da ${ }^{1} *$; OLIVEIRA, Ronaldo Lopes ${ }^{2}$; CARVALHO, Gleidson Giordano Pinto de ${ }^{2}$; RIBEIRO, Ossival Lolato ${ }^{2}$; LEÃO, André Gustavo ${ }^{2}$; FARIA, Mário Marcos de Santana ${ }^{1}$, LEDO, Carlos Alberto da Silva ${ }^{3}$

\author{
${ }^{1}$ Instituto Federal de Educação Ciência e Tecnologia Baiano, Catu, Bahia, Brasil. \\ ${ }^{2}$ Universidade Federal da Bahia, Escola de Medicina Veterinária, Departamento de Produção Animal, Salvador, \\ Bahia, Brasil. \\ ${ }^{3}$ Embrapa Mandioca e Fruticultura, Cruz das Almas, Bahia, Brasil. \\ *Endereço para correspondência: rluizvaz@gmail.com
}

\section{RESUMO}

Com o objetivo de verificar o nível mais adequado de inclusão da torta de dendê no concentrado de vacas em lactação a pasto, utilizaram-se 16 vacas multíparas leiteiras cruzadas das raças Gir e Holandês, com peso médio de $436,6 \mathrm{~kg}( \pm 59,7)$ em delineamento experimental quadrado latino, com as vacas distribuídas em quatro quadrados latinos, $4 \times 4$ simultâneos (quatro tratamentos $\mathrm{x}$ quatro períodos $\mathrm{x}$ quatro animais em cada tratamento). Foram avaliados a degradabilidade ruminal e o balanço energético em condições de pastejo, suplementado com concentrado, que continham os níveis de $0 ; 25 ; 50$ e $75 \%$ de torta de dendê. Os valores das frações A, B e c na MS da torta de dendê foram 2,41, 66,65 e 0,0272\% respectivamente. As degradabilidades potencial (DP) e efetiva (DE) da MS da torta de dendê foram: DP $(69,06 \%)$, DE $2 \% / \mathrm{h}$ $(40,84 \%) ; 5 \% / \mathrm{h}(25,91 \%)$ e $8 \% / \mathrm{h}(19,34 \%)$, as frações B e I, 66,65\% e 30,94\% respectivamente. A disponibilidade energética para lactação e o consumo líquido de energia diminuíram linearmente com a inclusão de torta de dendê. $\mathrm{O}$ balanço energético, embora positivo, correlacionou-se negativamente com os todos os níveis inclusão de torta de dendê. O melhor nível de inclusão da torta de dendê é o zero. Contudo, na prática pode-se indicar o nível de $25 \%$ de torta de dendê no suplemento concentrado para vacas em lactação a pasto pela proximidade dos valores de disponibilidade energética com o nível mais adequado $(0 \%$ torta de dendê).

Palavras-chave: coprodutos, estimativa energética, nutrição de ruminantes

\section{SUMMARY}

With the objective to verify the most appropriate level of palm kernel cake inclusion in the concentrate of dairy cows on pasture, 16 multiparous dairy cows crossbreed Gir and Holstein were used, with average weight of $436.6 \mathrm{~kg}( \pm 59.7)$ in latin square design, with the cows distributed in four Latin squares $(4 \times 4$ simultaneous; four treatments $\mathrm{x}$ four periods $\mathrm{x}$ four animals in each treatment). Ruminal degradability and energy balance were evaluated under grazing conditions, supplemented with concentrate, containing levels of $0,25,50$ and $75 \%$ of palm kernel cake. The values of fractions $\mathrm{A}, \mathrm{B}$ and $\mathrm{C}$ in $\mathrm{DM}$ of palm kernel cake were $2.41,66.65 \%$ and 0.0272 respectively. Potential and effective degradability of DM of palm kernel cake were: PD (69.06\%) of ED $2 \% / \mathrm{h}(40.84 \%)$ $5 \% / \mathrm{h}(25.91 \%)$ and $8 \% / \mathrm{h}(19.34 \%)$, fractions B and I, $66.65 \%$ and $30.94 \%$ respectively. Energy availability for lactation and net energy intake linearly decreased with palm kernel cake inclusion. Energy balance although positive was negative correlated to all levels of palm kernel cake inclusion. The best level of palm kernel cake inclusion is zero. However, in practice, it can be indicated the level of $25 \%$ of palm kernel cake in concentrate supplement for lactating cows on pasture, by the proximity of energy availability values with the most appropriate level ( $0 \%$ palm kernel cake).

Keywords: coproducts, energy estimate, ruminants nutrition 


\section{INTRODUÇÃO}

Estudos de degradação permitem determinar as frações, as taxas e a extensão da degradação ruminal dos alimentos (PIRES et al., 2010). Estimativas dos valores de energia dos alimentos e do balanço energético das dietas são importantes para vacas leiteiras, por ser uma categoria animal que requer grande quantidade de energia. Déficits ou excessos podem reduzir a produção de leite, causar perda de peso, problemas reprodutivos, diminuição da resistência a doenças (CAPELLE et al., 2001) e provocar o acúmulo de gordura e ou problemas metabólicos (WEISS, 1998).

O NRC (2001) propôs um método somativo para estimativa do NDT que pode ser calculado usando a energia produzida pelas frações químicas do alimento (carboidratos fibrosos, carboidratos não-fibrosos, lipídeos e proteína bruta), medidas ou determinadas por meio de análise de laboratório, e de suas digestibilidades verdadeira (valores conhecidos ou calculados), a partir de equações. Assim é possível estimar a energia disponível para os animais e calcular o balanço energético das dietas.

A utilização de coprodutos tem sido considerada uma alternativa promissora para alimentação de ruminantes, devido aos aspectos qualitativos relacionados às suas composições químico-bromatológicas, além do seu baixo custo e estabilidade de oferta ao longo do ano. Nesse contexto, a torta de dendê constitui uma alternativa para nutrição de ruminantes (RODRIGUES FILHO et al.,2001). A produção de óleo de palmiste, encontrado nas sementes do fruto do dendê, origina o coproduto torta de dendê, que tem como características teores de PB menores que $20 \%$ e FDN acima de $60 \%$, assim, esse ingrediente pode ser incluído entre os concentrados energéticos.

Estudos de degradação com a determinação das frações, taxas e extensão da degradação ruminal de coprodutos, como a torta de dendê, em concomitância à aplicação da metodologia proposta pelo NRC (2001) para estimativa da disponibilidade energética, pode contribuir para determinar o nível mais adequado de inclusão da torta de dendê nos suplementos concentrados, aperfeiçoar sua utilização na dieta de vacas em lactação a pasto e permitir estimativas acuradas da disponibilidade da energia contida nos alimentos (COSTA et al., 2005).

Nesse experimento, almejou-se determinar o melhor nível de inclusão da torta de dendê no suplemento concentrado de vacas em lactação a pasto, por intermédio da degradabilidade ruminal da matéria seca e fibra em detergente neutro e do balanço energético das dietas.

\section{MATERIAL E MÉTODOS}

O experimento foi realizado de julho a setembro de 2009, na Fazenda Experimental da Escola de Medicina Veterinária da Universidade Federal da Bahia (UFBA), situada no $\mathrm{Km} 174$ da rodovia BR 101, Distrito de Mercês, Município de São Gonçalo dos Campos (BA), localizada na latitude $12^{\circ} 23^{\prime} 58^{\prime \prime}$ sul e longitude $38^{\circ} 52^{\prime}$ 44 " oeste, situada na mesorregião do CentroNorte Baiano e microrregião de Feira de Santana-BA, distando $108 \mathrm{~km}$ de Salvador. O clima regional varia de úmido e subúmido até seco, de acordo com a classificação climática de Wilhelm Köppen, é do tipo As. As unidades geomórficas, características dos solos da região, são formadas pelos tabuleiros interioranos e pré-litorâneos (SEI, 2011), o que confere à fazenda experimental topografia plana.

Foram utilizadas 16 vacas leiteiras cruzadas das raças Gir e Holandês $1 / 2$ sangue, multíparas, com peso médio de $436,6 \mathrm{~kg}$ $( \pm 59,7)$. As vacas no início do período experimental estavam entre o pico e a fase 
intermediária de lactação. $\mathrm{O}$ rebanho experimental, 10 dias antes do período de adaptação foi vermifugado (Ivermectina a $1 \%$ ) e suplementado com solução injetável de vitaminas A, D, E, em concomitância com tônico composto comercial, que contém sais minerais, vitaminas do complexo B e aminoácidos. $\mathrm{O}$ período experimental foi de 60 dias divididos em quatro períodos de 15 dias, dos quais 11 dias de adaptação e 4 dias de coleta. As vacas foram distribuídas em quatro quadrados latinos, $4 \times 4$ simultâneos (quatro tratamentos $\mathrm{x}$ quatro períodos $\mathrm{x}$ quatro animais em cada tratamento).

Os animais foram manejados em sete piquetes de capim-Massai (Panicum maximum cv. Massai), com área de 1,93ha, delimitados por cerca elétrica, em sistema rotacionado, com cinco dias de ocupação e
35 dias de descanso. Todos os piquetes eram dotados de pontos de sombreamento com oferta de água e suplementação mineral à vontade. $\mathrm{O}$ pasto foi manejado pelo sistema de lotação variável, e foram utilizados, quando necessário, animais reguladores para ajuste da oferta forrageira a fim de proporcionar uma oferta de $8 \%$ do peso vivo em MS.

Os alimentos utilizados como ingredientes no suplemento concentrado foram torta de dendê, farelo de soja e milho moído. A torta de dendê foi incluída nos níveis de $0 ; 25 ; 50$ e $75 \%$ no concentrado.

A composição química dos ingredientes experimentais e da forragem encontra-se na Tabela 1. Os dados da composição percentual e química do suplemento concentrado estão registrados na Tabela 2 .

Tabela 1. Composição química dos ingredientes experimentais e da forragem de capim-Massai

\begin{tabular}{lccrc}
\hline \multirow{2}{*}{ Item (\% MS) } & \multicolumn{4}{c}{ Alimentos } \\
\cline { 2 - 5 } & Torta de dendê & Farelo de soja & Milho & Forragem \\
\hline Matéria seca (MS) & 93,20 & 89,55 & 89,26 & 28,46 \\
Matéria orgânica (MO) & 91,07 & 88,37 & 87,58 & 85,97 \\
Cinzas (Cz) & 2,13 & 1,18 & 1,68 & 7,50 \\
Proteína bruta (PB) & 9,98 & 46,64 & 7,53 & 6,58 \\
Extrato etéreo (EE) & 12,23 & 5,50 & 1,34 & 2,75 \\
FDN & 71,13 & 16,44 & 19,52 & 79,70 \\
FDNcp & 63,56 & 10,54 & 11,56 & 75,73 \\
FDNi & 40,82 & 1,66 & 9,53 & 23,32 \\
NIDN (\% NT) & 46,87 & 10,04 & 19,75 & 21,98 \\
FDA & 55,73 & 7,18 & 4,69 & 38,60 \\
NIDA (\% NT) & 17,72 & 3,58 & 3,94 & 16,06 \\
Lignina (LIG) & 17,03 & 5,91 & 3,80 & 12,39 \\
Celulose (CEL) & 38,71 & 1,27 & 0,89 & 26,21 \\
Hemicelulose & 7,83 & 3,36 & 6,87 & 37,13 \\
Sílica & 0,46 & - & - & - \\
Cz insolúvel detergente neutro (CzDN) & 2,84 & - & - & - \\
Carboidratos não fibrosos (CNF) & 12,10 & 36,14 & 79,59 & 7,73 \\
Carboidratos totais (CT) & 68,86 & 36,23 & 80,33 & 76,63 \\
\hline
\end{tabular}

Milho = grão de milho moído; FDNcp = fibra em detergente neutro corrigida para cinzas e proteína; FDNi $=$ fibra em detergente neutro indigestível; NIDN = nitrogênio insolúvel em detergente neutro; \% $\mathrm{NT}=$ percentual do nitrogênio total; FDA = fibra em detergente ácido; $\mathrm{NIDA}=$ nitrogênio insolúvel em detergente ácido; $\mathrm{CzDN}$ = cinza insolúvel em detergente neutro. 
Tabela 2. Composição percentual e química do suplemento concentrado

\begin{tabular}{lrrrr}
\hline \multirow{2}{*}{ Ingredientes (\% MS) } & \multicolumn{4}{c}{ Níveis de torta de Dendê (\%) } \\
\cline { 2 - 5 } & \multicolumn{1}{c}{0} & \multicolumn{1}{c}{25} & 50 & \multicolumn{1}{c}{75} \\
\hline Grão de Milho moído & 80,17 & 59,65 & 39,14 & 18,63 \\
Farelo de Soja & 13,99 & 9,50 & 5,02 & 0,53 \\
Torta de Dendê & 0,00 & 25,00 & 50,00 & 75,00 \\
Mistura Mineral & 3,00 & 3,00 & 3,00 & 3,00 \\
Uréia & 2,57 & 2,57 & 2,57 & 2,57 \\
Sulfato de Amônio & 0,27 & 0,27 & 0,27 & 0,27 \\
\hline Total & 100 & 100 & 100 \\
\hline Item (\% MS) & 0 & 25 & 50 & 100 \\
\hline Matéria Seca (MS) & 89,86 & 90,88 & 91,69 & 92,53 \\
Matéria Orgânica (MO) & 88,34 & 89,23 & 89,91 & 90,61 \\
Proteína Bruta (PB) & 19,96 & 18,86 & 17,71 & 16,56 \\
Extrato Etéreo (EE) & 1,81 & 4,36 & 6,91 & 9,45 \\
Cinzas (Cz) & 1,52 & 1,12 & 0,72 & 0,32 \\
Fibra em Detergente Neutro (FDN) & 10,79 & 25,73 & 40,65 & 55,57 \\
FDN indigestível (FDNi) & 7,92 & 16,10 & 24,25 & 32,41 \\
Carboidratos Não Fibrosos (CNF) & 71,69 & 56,13 & 40,40 & 24,70 \\
Carboidratos totais (CT) & 69,83 & 68,95 & 67,92 & 66,90 \\
Nutrientes digestíveis totais (NDT) & 78,74 & 75,50 & 72,07 & 68,67 \\
Energia metabolizável (Mcal/kg) & 3,40 & 3,00 & 2,60 & 2,55 \\
Energia Líquida lactação M(Mcal/kg) & 2,20 & 1,92 & 1,64 & 1,60 \\
\hline Mcalkg
\end{tabular}

$\mathrm{Mcal} / \mathrm{kg}=$ megacaloria por quilograma.

O suplemento concentrado foi oferecido na quantidade de $3,0 \mathrm{~kg}$ por dia, durante os 15 dias de cada período experimental em duas refeições diárias, às $6 \mathrm{~h}$ e às $15 \mathrm{~h}$, durante as ordenhas. A estimativa da produção fecal e subsequente determinação do consumo de matéria seca total foi realizada a partir do $5^{\circ}$ dia, por intermédio do fornecimento via oral de $10 \mathrm{~g}$ de óxido crômico em duas doses diárias de $5 \mathrm{~g}$ (em papelotes), até a manhã do $15^{\circ}$ dia. Durante os quatro dias do período de coleta, cerca de $200 \mathrm{~g}$ de fezes foram recolhidas diretamente da ampola retal dos animais, duas vezes ao dia, às $6 \mathrm{~h}$ e às $12 \mathrm{~h}$ do primeiro dia de coleta, com incremento de duas horas a cada dia de coleta subsequente. Desse modo, foram realizadas oito amostragens/animal/período, e o material coletado foi em seguida acondicionado em sacos plásticos identificados, e armazenados em freezer a $-20^{\circ} \mathrm{C}$. Posteriormente, as amostras de fezes foram descongeladas e secas em estufa a $55^{\circ} \mathrm{C}$.

Após a desidratação, as amostras foram moídas $(1 \mathrm{~mm})$ e compostas com base no peso seco ao ar, por animal, tratamento e período, e analisadas quanto ao teor de cromo em espectrofotômetro de absorção atômica (WILLIAMS et al., 1962). Utilizouse como indicador interno a fibra em detergente neutro indigestível (FDNi) para avaliação do consumo, para isso foram utilizados dois bovinos Girolandos, 1/2 sangue machos castrados, com peso vivo médio de $500 \mathrm{~kg}( \pm 22)$, fistulados no rúmen, de acordo com a metodologia empregada por Detmann et al. (2004a), alimentados com feno de tifton 85 e concentrado com torta de dendê.

A metodologia consistiu na incubação in situ das amostras (ingredientes dos suplementos, forragens e fezes) por $144 \mathrm{~h}$, e posteriormente, 
submetidas ao tratamento térmico com solução de detergente neutro, durante uma hora, assumindo o resíduo como indigestível. Para incubação utilizou-se sacos de TNT, gramatura 100 , medindo de $11 \times 6 \mathrm{~cm}$, nos quais foram depositados de 4 a 5 gramas de MS das amostras

As estimativas do consumo foram obtidas pela seguinte equação:

CMS $(\mathrm{kg} / \mathrm{dia})=\{[(\mathrm{PF} * \mathrm{CIF})-\mathrm{IS}] / \mathrm{CIFO}\}+$ CMSS

Em que: $\mathrm{CMS}=$ consumo de matéria seca (kg/dia); PF = produção fecal (kg/dia); CIF $=$ concentração fecal de FDNi $(\mathrm{kg} / \mathrm{kg}$ de $\mathrm{MS}$ ); IS = indicador (FDNi) no suplemento $(\mathrm{kg} / \mathrm{dia}) ; \mathrm{CIFO}=\mathrm{FDNi}$ na forragem $(\mathrm{kg} / \mathrm{kg}$ de MS); CMSS = consumo de matéria seca do suplemento ( $\mathrm{kg} / \mathrm{dia})$.

A digestibilidade aparente (D) da MS e dos nutrientes necessários as determinações energéticas foram calculados segundo Gobesso et al. (2011): $\mathrm{D}=[(\mathrm{kg}$ de nutriente ingerido $-\mathrm{kg}$ de nutriente excretado)]/ ( $\mathrm{kg}$ de nutriente ingerido) $\mathrm{X} 100$.

A avaliação qualitativa da forragem consumida pelos animais foi realizada por meio de pastejo simulado, assumindo-se que representassem material similar ao que estava sendo ingerido pelos animais. Assim, acompanhava-se um animal de cada um dos quatro grupos experimentais por 30 minutos e procurava-se coletar manualmente uma porção de forragem, semelhante à ingerida pelo animal, mediante simulação da sua ação de pastejo (CLIPES et al., 2005). A amostra resultante era armazenada e, posteriormente, reunida em uma amostra composta para análise de sua composição química e utilização nos estudos de degradação.

A degradabilidade ruminal foi obtida pela utilização de dois bovinos Girolandos, $1 / 2$,sangue machos castrados, com peso vivo médio de 500kg $( \pm 22)$. Amostras dos ingredientes foram acondicionadas em sacos $11 \times 5 \mathrm{~cm}$, confeccionados em fibra sintética (TNT), gramatura $100\left(100 \mathrm{~g} / \mathrm{m}^{2}\right)$ na proporção de 15 a $20 \mathrm{mg}$ de amostra por $\mathrm{cm}^{2}$ de área de saco, (NOCEK, 1988). As amostras foram moídas em peneira de $2 \mathrm{~mm}$ (concentrados) e $3 \mathrm{~mm}$ (forragem) e incubadas nos tempos $0 ; 3$; $6 ; 9 ; 12 ; 24 ; 48 ; 72 ; 96 ; 120 ; 144$ horas, sendo que o tempo zero correspondeu à lavagem dos sacos em água corrente para determinação da fração solúvel da matéria seca (CASALI et al., 2009). Os saquinhos foram inseridos em um saco maior de malha de poliéster, $20 \times 30 \mathrm{~cm}$ dotados de cordão para fechamento da boca e presos com abraçadeiras plásticas finas a uma corrente de $1,3 \mathrm{~m}$ de comprimento pesando cerca de 600 gramas. Em seguida as correntes foram presas a um fio de nylon duplo de $1 \mathrm{~mm}$ com $2,5 \mathrm{~m}$ de comprimento e incubadas no rúmen dos animais. A parte do fio de nylon exteriorizada na fístula, foi amarrada fixamente a um bastão de madeira leve $(20 \mathrm{~cm})$, para permitir a tração da corrente e incubação dos saquinhos nos horários correspondentes. Para facilitar o manejo das amostras após a incubação, os saquinhos foram incubados na ordem inversa de tempo, ou seja, do maior para o menor, de modo que todos foram retirados e lavados concomitantemente. Após a lavagem, os saquinhos foram levados a uma estufa de ventilação forçada, a $55^{\circ} \mathrm{C}$ por 48 horas. Em seguida, registrou-se o peso e calculouse a fração degradada da matéria seca. $\mathrm{Na}$ amostra residual foi determinada a fibra em detergente neutro (SILVA \& QUEIROZ, 2002).

Os dados de degradabilidade in situ da matéria seca foram obtidos pela diferença observada entre as pesagens efetuadas antes e após a incubação ruminal e expressos em porcentagem. Os resultados obtidos sobre o desaparecimento da MS e FDN nos diferentes tempos de incubação, foram ajustados para uma regressão não linear, pelo método de Gauss-Newton, sendo os parâmetros não lineares "A", "B" e "c" estimados.

Por ser um modelo de crescimento assintótico de primeira ordem, que foi reparametrizado 
subdividindo o valor da assíntota em duas frações, "A" e "B", a taxa de degradação da MS foi calculada por meio da equação proposta por Ørskov \& McDonald (1979): $\mathrm{Dt}=\mathrm{A}+\mathrm{B}\left(1-\mathrm{e}^{\mathrm{ct} t}\right)$, em que: $\mathrm{Dt}=$ fração degradada no tempo " $\mathrm{t}$ " (\%), "A" = fração solúvel $(\%) ;$ "B" = fração insolúvel potencialmente degradável $(\%)$; "c" = taxa de degradação da fração " $B$ " por ação fermentativa $(\% / h)$; e " $\mathrm{t}$ " = tempo $(\mathrm{h})$. Para a degradação da FDN em razão da inexistência da fração " $A$ " nesta, foi aplicado o modelo de Mertens \& Loften (1980): Rt $=B^{*} \mathrm{e}^{-\mathrm{ct}}+\mathrm{I}$, em que: $\mathrm{Rt}=$ fração degradada no tempo " $\mathrm{t}$ " (\%); I = fração indegradável; e "B", "c" e "t" já previamente definidas. A degradabilidade efetiva (DE) da MS no rúmen foi calculada com utilização do modelo: $\mathrm{DE}=\mathrm{A}+(\mathrm{B} * \mathrm{c} / \mathrm{c}+\mathrm{k})$, em que: $\mathrm{k}$ corresponde à taxa de passagem das partículas no rúmen Orskov et al. (1980). Para a DE da FDN, foi utilizado o modelo: $\mathrm{DE}=\mathrm{B}^{*} \mathrm{c} /(\mathrm{c}+\mathrm{k})$, em que "B" é a fração potencialmente degradável (\%). Mertens \& Loften (1980).

A estimativa energética (NDT) das dietas foi realizada por intermédio da digestibilidade aparente medida de cada nutriente por meio indireto, e o fluxo fecal estimado mediante uso do indicador externo $\left(\mathrm{Cr}_{2} \mathrm{O}_{3}\right)$. O NDT observado foi obtido a partir da equação somativa utilizada pelo sistema NRC (2001): $\mathrm{NDT}=\mathrm{PBD}+2,25 *$ EED + FDNcpD + CNFD, onde FDNcp significa fibra em detergente neutro digestível, corrigida para cinzas e proteína, e CNFD é equivalente à carboidratos não fibrosos digestíveis.

O NDT estimado a partir das equações do NRC (2001) constituiu o NDT predito, enquanto que o balanço de energia foi obtido pela mensuração entre o consumo de nutrientes e a estimativa das exigências nutricionais (NRC, 2001). O balanço energético foi calculado segundo Lucy et al. (1992), pela seguinte fórmula:

$\mathrm{BE}=\mathrm{EL}$ (cons.) - EL (mant.) - EL (prod. leite).
Em que: EL (cons.) = energia líquida consumida (Mcal/dia), estimada como o CMS (kg/dia) multiplicado pela EL da dieta (Mcal/dia); EL (mant.) = energia líquida para mantença (Mcal $/ \mathrm{kg}$ ), calculada como $\mathrm{PV}^{0,75}$ multiplicado por 0,08 ; $\mathrm{EL}$ (prod. leite) $=$ produção diária de leite x $((0,0929 \times \% \mathrm{G})+$ $(0,0547 \times \% \mathrm{~PB})+0,192)$, onde: $\% \mathrm{G}=$ teor de gordura do leite; e $\% \mathrm{~PB}=$ teor de proteína do leite.

A partir da composição dos alimentos avaliados, foram estimados os valores de NDT, conforme equações do NRC (2001), que estima os teores de proteína bruta digestível (PBD), ácidos graxos digestíveis (AGD), fibra em detergente neutro isenta de proteínas digestível (FDNp) e carboidratos não-fibrosos digestíveis (CNFD), conforme descrito a seguir: PBD para alimentos volumosos = PB x Exp (-1,2 x (PIDA/PB)); em que PIDA = proteína insolúvel em detergente ácido; PBD para alimentos concentrados $=\mathrm{PB} \times[1-(0,4 \times \mathrm{PIDA} / \mathrm{PB})]$; $\mathrm{AGD}=(\mathrm{EE}-1) \times 100 ; \mathrm{CNFD}=0,98 \times \mathrm{CNF}$ $\mathrm{x}$ FAP; em que FAP = fator de ajuste para processamento físico, considerado para os alimentos utilizados neste trabalho igual a 1 (NRC, 2001); FDNpD = 0,75 (FDNp LIG) $\times$ [1- $\left.(\mathrm{LIG} / \mathrm{FDNp})^{0,667}\right]$; em que LIG = Lignina. Para estimar os nutrientes digestíveis totais de acordo com o NRC (2001), a equação utilizada foi: NDT $=$ PBD $+2,25 \mathrm{AGD}+\mathrm{FDNcpD}+\mathrm{CNFD}-7$; em que o valor 7 se refere ao NDT fecal metabólico.

As determinações de matéria seca (MS), matéria orgânica $(\mathrm{MO})$, nitrogênio total, extrato etéreo (EE), fibra em detergente neutro (FDN) dos alimentos, das sobras e das fezes, bem como, as estimativas de fibra em detergente ácido (FDA) e lignina dos alimentos foram realizadas conforme Silva \& Queiroz (2002). A hemicelulose foi calculada pela diferença entre os teores de FDN e FDA e a Lignina determinada em $\mathrm{H}_{2} \mathrm{SO}_{4}$ a $72 \%$. Os valores de nitrogênio insolúvel em detergente neutro (NIDN) e 
nitrogênio insolúvel em detergente ácido (NIDA) foram determinados nos resíduos obtidos após o tratamento das amostras, respectivamente, com detergente neutro ou ácido, nos quais observou-se os procedimentos preconizados por Pereira \& Rossi Júnior (1994), o que permitiu a obtenção da fibra em detergente neutro isenta de cinzas e proteínas (FDNcp). O carboidratos totais (CT) foram calculados segundo Sniffen et al., (1992). Já os carboidratos não fibrosos (CNF) foram calculados de acordo com Weiss (1998), como: $\mathrm{CNF}(\%)=100-(\% \mathrm{FDNcp}+\% \mathrm{~PB}+$ $\% \mathrm{EE}+\%$ cinzas).

As equações do NRC (2001) para estimativa do valor energético dos alimentos (NDT) foram avaliadas a partir da comparação dos valores observados in vivo (estimativa indireta da produção fecal por meio de indicadores), com os valores estimados por meio das equações. O procedimento de avaliação das equações do NRC (2001) foi feito por intermédio da regressão dos valores preditos sobre os observados.

Os dados dos parâmetros de energia e do balanço energético foram analisados mediante uso dos procedimentos GLM (General Linear Models) e REG (Regression) - (SAS INSTITUTE, 2004). A escolha dos modelos de regressão foi realizada pelo seu grau de ajuste, com base no coeficiente de determinação ajustado $\left(\operatorname{adj}-R^{2}\right)$, na significância da regressão, testada pelo teste $\mathrm{F}$, e na significância dos coeficientes de regressão pelo teste $\mathrm{t}$.

\section{RESULTADOS E DISCUSSÃO}

A massa de forragem observada durante o experimento foi em média $8.722 \mathrm{~kg} \mathrm{MS} / \mathrm{ha}$ com oferta média de $8,32 \%$ do PV em MS de foragem, portanto a meta de oferta forrageira foi alcançada, o que está de acordo com Silva et al. (2009) que preconizaram uma oferta de forragem de 6 a 9\% do PV para vacas leiteiras em Penissetum purpureum cv. anão.

Os valores das frações "A", "B" e c na MS da torta de dendê foram 2,41\%,66,65\% e $0,0272(\% / \mathrm{h})$ (Tabela 3). O baixo valor da fração $\mathrm{A}$, neste trabalho, pode ser creditado ao alto conteúdo de fibra (FDN, 71,13\%), $40,8 \%$ deste percentual, indigestível, ao expressivo teor de lignina $(17,03 \%)$ que associados compuseram uma matriz de difícil degradação e ao baixo teor de CNF $(12,10 \%)$ da torta de dendê. Ao avaliarem a degradabilidade potencial e efetiva do farelo de Cacau e da torta de dendê, Pires et al. (2003) verificaram que esses alimentos apresentaram baixo aproveitamento no rúmen, o que lhes permitiu atribuir esse comportamento ao elevado conteúdo fibroso, altamente lignificado, no qual estão contidos boa parte dos compostos nitrogenados naqueles alimentos.

Os valores encontrados para as degradabilidades potencial e efetiva da MS da torta de dendê foram: DP $(69,06 \%)$, DE $2 \% / \mathrm{h}$ $(40,84 \%) ; 5 \% / \mathrm{h}(40,84 \%)$ e $8 \% / \mathrm{h}(19,34 \%)$, frações B $(66,65 \%)$ e I $(30,94 \%)$. Para a FDN da torta de dendê foram: DP $(69,73 \%)$, DE $2 \% / \mathrm{h} \quad(29,05 \%) ; \quad 5 \% / \mathrm{h} \quad(15,49 \%)$ e $8 \% / \mathrm{h}$ $(10,56 \%)$, frações B $(69,72 \%)$ e I $(30,28 \%)$. Por sua vez, Carvalho et al. (2006), ao trabalharem com torta de dendê encontraram valores de DP $(76,95 \%)$, DE $(18,91 \%)$, frações A, B, I e c de 7,6; 69,3, 23,1\% e $0,009 \% / \mathrm{h}$ respectivamente, enquanto para FDN os valores corresponderam a DP (58,7\%); DE (25,7\%); B (58,7\%), I (41,3\%) e c $(0,979 \% / \mathrm{h})$. Os valores reportados demonstram a variabilidade entre os dados observados. Isso decorre de variações na composição da torta de dendê ofertada no mercado, isto é, em função de componentes de natureza física (presença de cascas e outras impurezas) e nos teores de óleo residual, que se devem à inexistência de padrões de manufatura estabelecidos em normas e regras rígidas de fabricação (Figura 1). 
Tabela 3. Frações, degradabilidade potencial e degradabilidade efetiva da torta de Dendê (Eleais guineenses Jacq) e do capim-Massai (Panicum maximum cv. Massai)

\begin{tabular}{|c|c|c|c|c|c|c|c|c|c|c|}
\hline \multirow{3}{*}{ Alimentos } & & \multicolumn{9}{|c|}{ Parâmetros } \\
\hline & & \multirow{2}{*}{ A (\%) } & \multirow{2}{*}{$\begin{array}{l}\mathrm{B} \\
(\%)\end{array}$} & \multirow{2}{*}{$\begin{array}{c}\mathrm{c} \\
(\% / \mathrm{h})\end{array}$} & \multirow{2}{*}{$\begin{array}{c}\mathrm{I} \\
(\%)\end{array}$} & \multicolumn{5}{|c|}{ DE } \\
\hline & & & & & & DP & $2 \%$ & $5 \%$ & $8 \%$ & $\mathrm{R}^{2}$ \\
\hline \multirow{2}{*}{$\begin{array}{l}{ }^{1} \text { torta de dendê } \\
{ }^{2} \text { capim-Massai }\end{array}$} & \multirow{2}{*}{ MS } & 2,41 & 66,65 & 0,0272 & 30,94 & 69,06 & 40,84 & 25,91 & 19,34 & 0,96 \\
\hline & & 2,23 & 64,81 & 0,0181 & 32,06 & 67,04 & 33,05 & 19,48 & 14,20 & 0,92 \\
\hline \multirow{2}{*}{ Alimentos } & & & B & $\mathrm{c}$ & I & \multicolumn{5}{|c|}{$\mathrm{DE}$} \\
\hline & & & $(\%)$ & $(\% / \mathrm{h})$ & $(\%)$ & DP & $2 \%$ & $5 \%$ & $8 \%$ & $\mathrm{R}^{2}$ \\
\hline \multirow{2}{*}{$\begin{array}{l}\text { torta de dendê } \\
{ }^{2} \text { capim-Massai } \\
\end{array}$} & \multirow{2}{*}{ FDN } & - & 69,72 & 0,0142 & 30,28 & 69,73 & 29,05 & 15,49 & 10,56 & 0,96 \\
\hline & & - & 80,24 & 0,0142 & 19,76 & 80,24 & 33,26 & 17,71 & 12,07 & 0,91 \\
\hline
\end{tabular}

$\mathrm{A}=$ fração solúvel, $\mathrm{B}=$ fração insolúvel potencialmente degradável, $\mathrm{c}=$ taxa de degradação de $\mathrm{B}$ por ação fermentativa, $\mathrm{I}$ = fração não degradável, $\mathrm{DP}$ = degradabilidade potencial, $\mathrm{DE}$ = degradabilidade efetiva.

a)

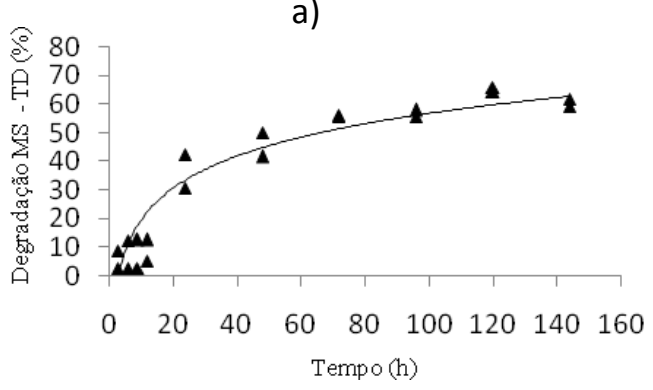

c)

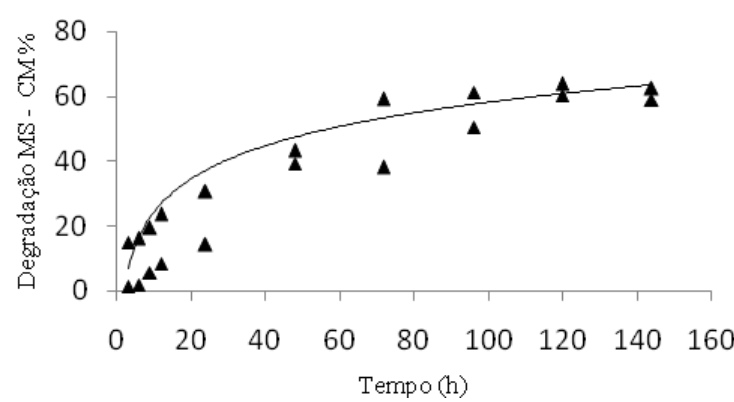

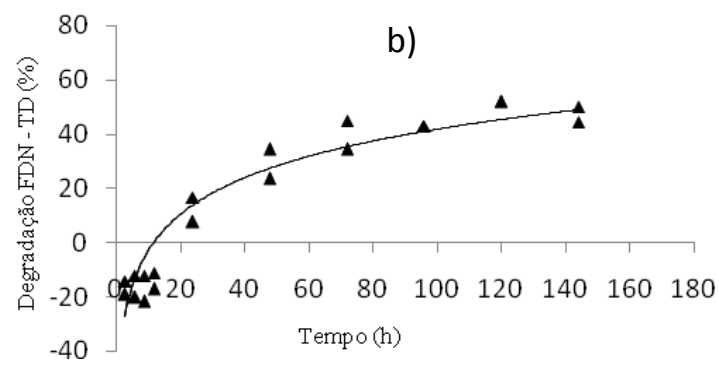

d)

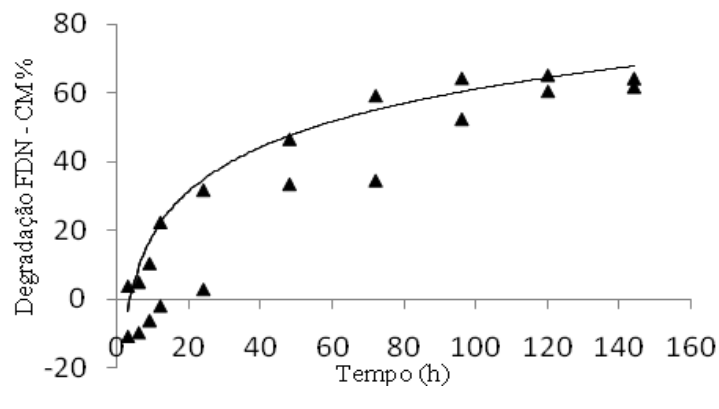

Figura 1. Assíntotas de degradação da MS e da FDN da torta de dendê (a e b) e do capim massai (c e d)

Pelas curvas de degradação da MS e FDN da torta de dendê e do capim-Massai (Figura1), verificou-se que $60 \%$ da degradação da MS dos dois alimentos ocorreu por volta de $144 \mathrm{~h}$ de incubação, enquanto que, apenas $45 \%$ da FDN da torta de dendê foi degradada nesse tempo. Por sua vez, a degradação da FDN do
capim-Massai foi mais extensa $65 \%$. Os períodos de latência discreta variaram conforme verificado nas figuras "b" e "d" de 10 a 21 horas para a FDN do capim-Massai e torta de dendê, respectivamente.

A demanda de energia para manutenção aumentou linearmente com os níveis de 
torta de dendê $(\mathrm{P}<0,05)$ - (Tabela) 4 . Aparentemente, à medida que o nível de energia suprido pela dieta decresceu, maior quantidade de energia foi destinada para manutenção, uma vez que, as funções vitais têm prioridade sobre a reprodução e ou ganhos de produção. A disponibilidade energética para lactação e o consumo líquido de energia não foram afetados com a inclusão crescente de torta de dendê $(\mathrm{P}<0,05)$ - (Tabela) 4. $\mathrm{O}$ balanço energético em particular correlacionou-se negativamente com os níveis de torta de dendê $(\mathrm{P}<0,05)$ - (Tabela 5), ocorrência relacionada ao aporte energético decrescente, conforme evidenciado por todos os parâmetros vinculados à energia, neste trabalho, exceto a fração extrato etéreo.

Tabela 4. Energia líquida de mantença $\left(\mathrm{EL}_{(\operatorname{mant})}\right)$, energia líquida para produção de leite $\left(\mathrm{EL}_{(\text {lactação) }}\right)$, consumo de energia líquida $\left(\mathrm{EL}_{\text {(consumida) }}\right)$ e balanço energético (BE) de vacas em lactação, com níveis de torta de dendê no concentrado

\begin{tabular}{|c|c|c|c|c|c|c|c|}
\hline \multirow{2}{*}{ Variáveis(Mcal $/ \mathrm{kg}$ ) } & \multicolumn{4}{|c|}{ Níveis de torta de dendê (\%MS) } & \multirow{2}{*}{${ }^{1} \mathrm{EPM}$} & \multicolumn{2}{|c|}{ Efeito } \\
\hline & 0 & 25 & 50 & 75 & & Linear & Quadrático \\
\hline${ }^{2} \mathrm{EL}_{\text {(mant.) }}$ & 6,46 & 6,70 & 7,01 & 7,06 & 0,0856 & 0,0033 & 0,4212 \\
\hline${ }^{3} \mathrm{EL}_{\text {(lactacão) }}$ & 6,81 & 6,70 & 6,28 & 6,08 & 0,0889 & 0,0058 & 0,3967 \\
\hline${ }^{4} \mathrm{EL}$ (consumida) & 22,08 & 18,23 & 14,58 & 13,21 & 0,9364 & 0,0032 & 0,1154 \\
\hline${ }^{5} \mathrm{BE}$ & 8,81 & 4,84 & 1,29 & 0,07 & 0,1102 & 0,0028 & 0,4541 \\
\hline
\end{tabular}

${ }^{1} \mathrm{EPM}$ - Erro padrão da média, ${ }^{2} \hat{\mathrm{Y}}=6,49+0,0085 \mathrm{TD} \mathrm{R}^{2}=0,93,{ }^{3} \hat{\mathrm{Y}}=6,86-0,0105 \mathrm{TD} \mathrm{R}^{2}=0,95,{ }^{4} \hat{\mathrm{Y}}=21,56-0,121 \mathrm{TD}$ $\mathrm{R}^{2}=0,96,{ }^{5} \hat{\mathrm{Y}}=8,218-0,1191 \mathrm{TD} \mathrm{R}^{2}=0,95$.

Tabela 5. Energia digestível (ED), energia metabolizável (EM), energia líquida para mantença $(\mathrm{ELm})$, energia líquida para lactação $\left(\mathrm{EL}_{\mathrm{L}}\right)$, nutrientes digestíveis totais $(\mathrm{NDT})$ predito e NDT observado, em ensaio de digestibilidade aparente de dietas contendo níveis de torta de dendê no concentrado

\begin{tabular}{lcccc}
\hline \multirow{2}{*}{ Indicador (Mcal/kg) } & \multicolumn{4}{c}{ Níveis de torta de dendê $(\%)$} \\
\cline { 2 - 5 } & 0 & 25 & 50 & 75 \\
\hline ED & 3,81 & 3,41 & 3,02 & 2,96 \\
EM & 3,40 & 3,00 & 2,60 & 2,55 \\
ELm & 2,35 & 2,03 & 1,70 & 1,65 \\
EL & 1,64 & 1,38 & 1,08 & 1,04 \\
${ }^{1}$ NDT predito & 84,73 & 75,84 & 66,78 & 65,92 \\
NDT Observado & 70,92 & 61,40 & 66,70 & 65,61 \\
\hline
\end{tabular}

${ }^{1}$ NDT predito pelo modelo NRC (2001).

Os valores de NDT preditos nos níveis 0 e $25 \%$, de torta de dendê, foram superiores em $16,29 \%$ aos observados (Tabela 5), enquanto que os valores nos níveis subsequentes 50 e $75 \%$ de torta de dendê foram idênticos. Essa discrepância pode ser creditada à diferenças qualitativas entre os ingredientes, notadamente o milho. Este, produzido em condições de clima temperado, tem endosperma farináceo, com maior taxa e extensão da degradação ruminal. 
Como as equações foram geradas em experimentos naquelas condições, tenderam a superestimar o valor energético na ausência ou com pequeno quantitativo do ingrediente na ração, comparado aos valores efetivamente observados (Figura 2.).

Os valores de NDT predito, mais elevados nos níveis 0 e $25 \%$ de torta de dendê e idênticos nos níveis 50 e $75 \%$ torta de dendê, são consistentes ao observado por Rocha Júnior et al. (2003) e Detmann et al. (2004b) que consideraram as equações indicadas para estimativa energética em alimentos tropicais. Porém, segundo Pereira et al. (2008), em virtude da variabilidade da composição química normalmente encontrada nos resíduos, seriam recomendadas mais pesquisas a respeito da utilização dessas equações, para que, a partir de um banco de dados maior, fosse possível maior eficácia das equações na predição do valor energético dos alimentos em condições brasileiras. O fato dos níveis da torta de dendê terem se correlacionado negativamente com parâmetros vinculados à energia, com efeito supressivo no consumo e digestibilidade aparente da MS, pressupõe que sua utilização deve ser criteriosa e pautada em limites estreitos de controle.

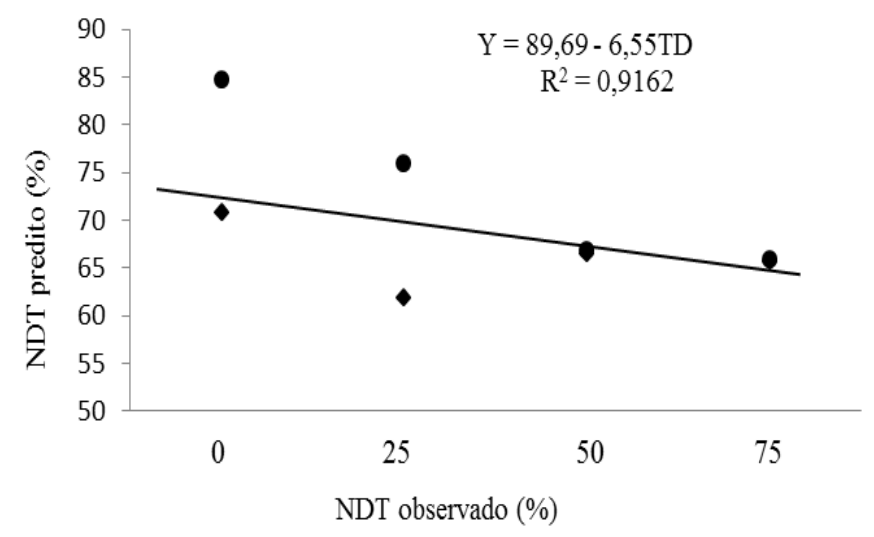

Figura 2. Relação entre os valores NDT preditos $(\bullet)$ pelo NRC (2001) e observados $(\diamond)$ para os suplementos concentrados com níveis 0,25 50 e $75 \%$ de torta de dendê

$\mathrm{O}$ alto conteúdo de fibra (FDN, 71,13\%) e o expressivo teor de lignina $(17,03 \%)$ da torta de dendê, que associados compõem uma matriz de difícil degradação, associados ao baixo teor de CNF (12,10\%), expressam menor eficiência de degradação ruminal, com necessidade de maior tempo de permanência no rúmen, para maior degradação. Dessa forma, menor inclusão de torta de dendê resulta em maior disponibilidade de nutrientes.

A torta de dendê por sua baixa degradabilidade ruminal e disponibilidade energética não é um ingrediente indicado para compor suplementos concentrados para vacas em lactação a pasto. Entretanto, na prática, valores de disponibilidade energética muito próximos entre o nível 0 e o $25 \%$ poderiam determinar sua inclusão nos concentrados até $25 \%$. 


\section{REFERÊNCIAS}

CAPELLE, E.R.; VALADARES FILHO, S.C.; SILVA, J.F.C.; CHACON, P.R. Estimativas do valor energético a partir de características químicas e bromatológicas dos alimentos. Revista Brasileira de Zootecnia, v.30, n.6, p.1837-1856, 2001.

CARVALHO, G.G.P.; PIRES, A.J.V.; VELOSO, C.M.; SILVA, R.R.; MENDES, F.B.L.; SOUZA, D.R.; PINHEIRO, A.A. Degradabilidade ruminal de concentrados e subprodutos agroindustriais. Archivos de Zootecnia, v.55, n.212, p.397-400, 2006.

CASALI, A.O.; DETMANN, E.; VALADARES FILHO, S.C.; PEREIRA, J.C.; CUNHA, M.; DETMANN, K. S. C.; PAULINO, M. P. Estimação de teores de componentes fibrosos em alimentos para ruminantes em sacos de diferentes tecidos. Revista Brasileira de Zootecnia, v.38, n.1, p.130-138, 2009.

CLIPES, R.C.; SILVA, J.F.C.; DETMANN, E.VASQUEZ, H.M.; SCOLFORO, L.; LOMBARDI, C.T. Avaliação de métodos de amostragem em pastagens de capim-elefante (Pennisetum purpureum, Schum) e capim-mombaça (Panicum maximum, Jacq) sob pastejo rotacionado. Arquivo Brasileiro de Medicina Veterinéria e Zootecnia, v.57, n.1, p.120-127, 2005.

COSTA, M.A.L.; VALADARES FILHO, S.C.; VALADARES, R.F.D.; PAULINO, M.F.; CECON; P.R.; PAULINO, P.V.R.; CHIZZOTTI, M.L.; PAIXÃO, M.L. Validação das Equações do NRC (2001) para predição do valor energético de alimentos nas condições brasileiras.

Revista Brasileira de Zootecnia, v.34, n.1, p.280-287, 2005.
DETMANN, E.; VALADARES FILHO, S.C.; PAULINO, M.F.; EUCLYDES, R.F.; LANA, R.P.; QUEIROZ, D.S. Avaliação da técnica dos indicadores na estimação do consumo por ruminantes em pastejo. Caderno Técnico de Veterinária e Zootecnia, n.45, p.40-57, 2004a.

DETMANN, E.; ZERVOUDAKIS, J.T.; CABRAL, L.S.; ROCHA JÚNIOR, V.R.; VALADARES FILHO, S.C.; QUEIROZ, A.C.; PONCIANO, N.J.; FERNANDES, A.M. Validação de equações preditivas da fração indigestível da fibra em detergente neutro em gramíneas tropicais. Revista Brasileira de Zootecnia, v.33, n.6, p.18661875, 2004b. Supl. 1.

GOBESSO, A.A.O.; RAMOS, S.C.; CASALECH, F.L.; MOREIRA, A.M. F.O.; BRANDI, R.A.; RENNÓ, F.P.; FREITAS JÚNIOR, J.E.F. Indicadores para estimativa da digestibilidade aparente total em equinos. Revista Brasileira de Saúde e Produção Animal [Online], v.12, n.1, p.264-274, 2011.

LUCY, M.C.; STAPLES, C.R.; THATCHER, W.W. ; ERICKSON, P.S.; CLEALE, R.M; FIRKINS, J.L.; CLARK, J.H.; MURPHY, M.R.; BRODIE, B.O. Influence of diet composition, dry-matter intake, milk production and energy balance on time of post-partum ovulation and fertility in dairy cows. Animal Production, v.54, p.323-331, 1992.

MERTENS, D.R.; LOFTEN, J.R. The effect of starch on forage fiber digestion kinetics in vitro. Journal of Dairy Science, v.63, p.1437-1446, 1980.

\section{NATIONAL RESEARCH COUNCIL -} NRC. Nutrient requirements of dairy cattle.7.ed. Washinton, DC.: National Academic Press, 2001. 381p. 
NOCEK, J. In situ and other methods to estimate ruminal protein and energy digestibility: a review. Journal of Dairy Science, v.71, p.2051-2069, 1988.

ØRSKOV, E.R.; McDONALD, I. The estimation of protein degradability in rumen from incubation measurements weighted according to rate of passage. Journal of Agricultural Science, v.92, p.449-453, 1979.

ØRSKOV, E.R.; HOVELL, F.D.D.; MOULD, F. Uso de la técnica de la bolsa de nylon para la avaluación de los alimentos. Production Animal Tropics, v.5, p.213-233, 1980.

PEREIRA, J.R.A.; ROSSI JÚNIOR, P. Manual de avaliação nutricional de alimentos. Piracicaba: Fundação de Estudos Agrários Luiz de Queiroz, 1994. $34 \mathrm{p}$.

PEREIRA, E.S.; REGADAS FILHO, J.G.L.; ARRUDA, A.M.V.; MIZUBUTI, I. Y.; VILLARROEL, A.B. S.; PIMENTEL, P.G.; CÂNDIDO, M.J.D. Equações do NRC (2001) para predição do valor energético de co-produtos da agroindústria no nordeste brasileiro.

Revista Brasileira de Saúde e Produção Animal [Online], v.9, n.2, p.258-269, 2008.

PIRES, A.J.V; CARVALHO, G.G.P; SILVA, R.C. Degradabilidade ruminal de matéria seca de concentrados e subprodutos agroindustriais. In: SEMINÁRIO DE INICIAÇÃO CIENTÍFICA, 7., 2003, Vistoria da Conquista. Anais... Vitória da Conquista: Universidade Estadual do Sudoeste da Bahia, 2003.
PIRES, A.J.V.; CARVALHO, G.G.P.; SIQUEIRA, G.R.; BERNARDES, T.F.; RUGGIERI, A.C.; ROTH, M.T.P.

Degradabilidade ruminal da matéria seca, da proteína bruta e da fração fibrosa de silagens de milho, de sorgo e de Brachiaria brizantha. Arquivo Brasileiro de Medicina Veterinária e Zootecnia, v.62, n.2, p.391400, 2010.

RODRIGUES FILHO, J.A.; CAMARÃO, A.P.; AZEVEDO, G.P.C. Utilização da torta de amêndoa de dendê na alimentação de ruminantes. Belém: Embrapa Amazônia Oriental, 2001. 24p. (Documentos, 111).

ROCHA JÚNIOR, V.R.; VALADARES FILHO, S.C.; BORGES, A.M.; MAGALHÃES, K.A.; FERREIRA, C.C.B.; VALADARES, R.F.D.; PAULINO, M.F. Determinação do valor energético de alimentos para ruminantes pelo sistema de equações. Revista Brasileira de Zootecnia, v.32, n.2, p.473-479, 2003.

SEI-BA. Informações geoambientais.

Disponível em: $<\underline{\text { http://www.sei.ba.gov.br>. }}$ Acesso em: 28 abr. 2011.

SILVA, D.J.; QUEIROZ, A.C. Análise de alimentos: métodos químicos e biológicos. Viçosa, MG: Universidade Federal de Viçosa, 2002. 235p.

SILVA, C.V.; LANA, R.P.; CAMPOS, J.M.S.; QUEIROZ, A.C.; LEÃO, M.I.; ABREU, D.C. Consumo, digestibilidade aparente dos nutrientes e desempenho de vacas leiteiras em pastejo com dietas com diversos níveis de concentrado e proteína bruta. Revista Brasileira de Zootecnia, v.38, n.7, p.1372-1380, 2009. 
SNIFFEN, C.J.; CONNOR, J.D.; VAN SOEST, P.J.; FOX, D.G.; RUSSELL, J.B. A net carbohydrate and protein system for evaluation of cattle diets. II Carbohydrate and protein availability. Journal Animal Science, v.70, n.3, p.3562-3577, 1992.

SAS INSTITUTE. SAS/STAT: user's guide: statistics. Release 9.1.2 Cary, 2004. $1500 \mathrm{p}$.
WEISS, W.P. Estimating the available energy content of feeds for dairy cattle. Journal of Dairy Science, v.81, p.830-839, 1998.

WILLIAMS, C.H.; DAVID, D.J.; ISMAA, $\mathrm{O}$. The determination of chromic oxide in feces samples by atomic absorption spectrophotometry. Journal of Agriculture Science, v.59, n.3, p.81-385, 1962.

Data de recebimento: 18/07/2011

Data de aprovação: 09/02/2012 